\title{
Qualified Analysis of DSMC over SMC for Boost Converter
}

\author{
Viji Karthikeyan ${ }^{1}$, Anil Kumar² and Nagaraj Ramrao ${ }^{3}$ \\ ${ }^{1}$ Assistant Professor, Department of Electrical and Electronics Engineering, \\ The Oxford College of Engineering, Bangalore, India \\ ${ }^{2}$ Director, Amity School of Engineering and Technology, Lucknow, India \\ 3Director, The Oxford Educational Institutions, Bangalore, India \\ ${ }^{1}$ kvijiperumal@gmail.com, ${ }^{2}$ akumar3@lko.amity.edu, ${ }^{3}$ nagaraj.ramrao@gmail.com
}

\begin{abstract}
A qualified analysis of Discrete Sliding Mode Controller (DSMC) over Sliding Mode Controller (SMC) for dc-dc boost Converter is described. The system is first designed with SMC with inner current loop and outer voltage loop control, secondly with the help of sample and hold circuit parameters are sampled and DSMC is used to regulate the output voltage. Both the cases output voltage is regulated and their response is analyzed for the step change in input to prove robustness of the controller. The main aim is to analyze the boost converter to prove its voltage regulation, to prove the robustness of the controller by giving step input, to obtain improved rate of response with better efficiency and to overcome the chattering phenomenon. The implementation of DSMC is simple which eliminates the requirement of $A D C$ and has flexible control characteristics for parameter variation so that the overall system is efficient \& cost-effective.
\end{abstract}

Keywords: Discrete Sliding Mode Controller, Sliding Mode Controller, DC-DC Converter, Boost Converter

\section{Introduction}

Now-a-Days Power electronics converters are commonly used because of its ease of implementation, high efficiency, and improved power factor, compact size, flexibility in control. The commonly used applications of power converters are variable speed AC and DC Drives, Induction heating, High Voltage Dc Transmission, Traction applications and Switched Mode Power Supply. Dc-Dc converters are one of the commonly used converters because of its simple circuit design and its ease of implementation. Boost converter is one among the DC-DC converters is used in this paper and its performance is analyzed with Sliding Mode Controller and Discrete Sliding Mode Controller, their response is compared.

The response of the power electronics converters are affected by (1) the non-linear characteristics of the switching devices like power diodes and power MOSFET what we are using in the boost converter (2) the inductance what we are using in the circuit may saturate which can cause non-linearity (3) the capacitance used for filtering purpose leads to clamping of voltage across it results in non-linear characteristics.

The non-linearity can be overcome with the help of Sliding Mode Controller, which is a part of variable structure system because the system is less sensitivity towards non-linearity $[1,2]$. Even systems with unknown parameters can modeled with the help of SMC which requires only approximate equivalent design to model it, and all the higher order systems are

Received (July 26, 2017), Review Result (November 4, 2017), Accepted (November 24, 2017) 
reduced into first order for SMC design which results in simplicity of the design. The system shows excellent robustness against parameter fluctuations, so the non-linearity problems of power converters are overcome by this controller. The only problem what we are facing is nothing but the chattering phenomenon, which is because of the controller switches across the sliding line in order to track the path.

The DSMC is introduced which eliminates the need for ADC, has flexible control algorithm, ease of implementation, reduced ripples in the output so that the efficiency of the system is improved $[3,4]$.

\section{Block Diagram Description and Methodology}

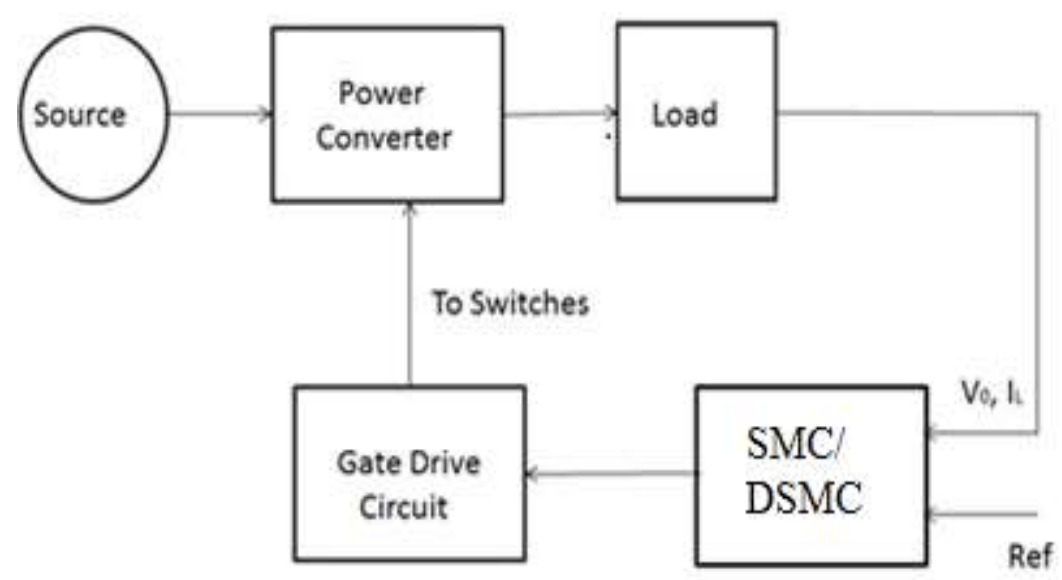

Figure 1. Block Diagram of SMC/DSMC

Figure 1 shows the block diagram description of SMC/DSMC. The power converter is the DC-DC Boost converter, so the input is the DC source which can be a battery or it can be an AC source also. In that case controlled or uncontrolled rectifier can be used. In case of controlled rectifier thyristor is used as a switch, by varying the firing angle we can control the voltage given as input to the boost converter whereas in case of un-controlled rectifier diode is used as a switch AC is converter into un-controlled DC. In boost converter power MOSFET is used as a switch, the signal is generated by the gate drive circuit after getting command from the SMC/DSMC.

The load is selected as a resistive load; the parameters to be controlled are inductor current and capacitor voltage or output voltage. These parameters are sensed and the error $\mathrm{e}_{1}$ is measured which is the difference between the actual voltage and the reference voltage. With the help of error $\mathrm{e}_{1}$; the current reference is calculated and then the error $\mathrm{e}_{2}$ which is the difference between the measured value and the reference value is measured. So the system is having inner current value and outer voltage loop, using the error signals the sliding surface is calculated.

If it is the DSMC then S/H circuit is used before and after the boost converter, the variables are sampled and the sampled values are compared with the reference and the errors are calculated; the sliding surface is designed. Finally control signal is calculated which is sampled and given to the gate drive circuit then to the gate of the power MOSFET. 


\section{Design of SMC based Boost Converter}

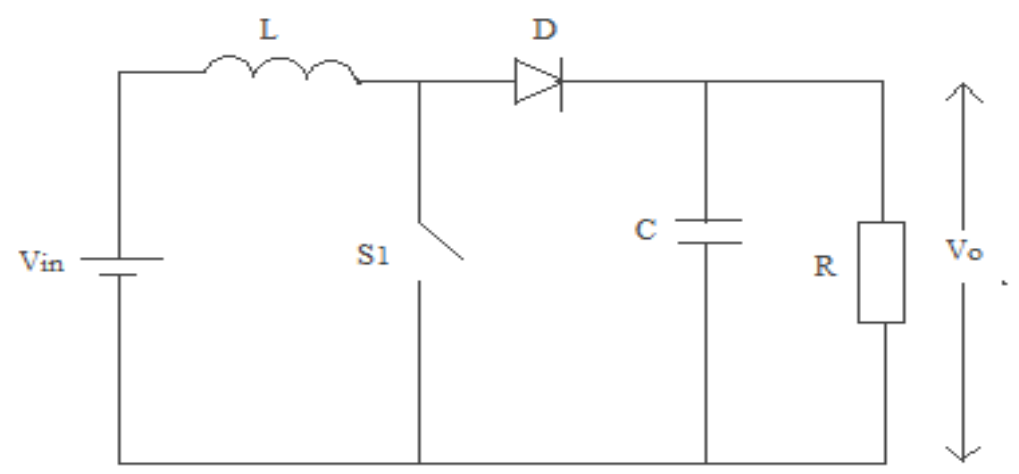

Figure 2. Circuit Diagram of Boost Converter

Figure 2 shows the circuit diagram description of the boost converter, which has input voltage $\mathrm{V}_{\text {in }}$, inductor L, Diode $\mathrm{D}$, capacitor $\mathrm{C}$, switch $\mathrm{S}_{1}$, load resistance $\mathrm{R}$ [5]. During the On state of the switch, the system is represented by the following equations $(1,2)$

$$
\begin{aligned}
& \frac{d i_{L}}{d t}=\frac{V_{\mathrm{in}}}{L} \\
& \frac{d V_{0}}{d t}=-\frac{V_{0}}{R C}
\end{aligned}
$$

When $S_{1}$ is OFF the system is represented by the following equations $(3,4)$

$$
\begin{array}{r}
\frac{d i_{L}}{d t}=\frac{V_{\mathrm{in}}}{L}-\frac{(1-u)}{L} V_{0} \\
\frac{\mathrm{dV} V_{0}}{\mathrm{dt}}=\frac{1}{\mathrm{C}}\left[(1-\mathrm{u})_{\mathrm{L}}-\frac{\mathrm{V}_{0}}{\mathrm{R}}\right]
\end{array}
$$

Using KVL the loop equations are formed, from that we can write

$$
\begin{aligned}
& \dot{x}_{1}(\mathrm{t})=\frac{1}{\mathrm{~L}}\left[\mathrm{~V}_{\mathrm{in}}-(1-\mathrm{u}) x_{2}\right] \\
& \dot{x}_{2}(\mathrm{t})=-\frac{1}{C}\left[\frac{x_{2}}{R}-(1-u) x_{1}\right]
\end{aligned}
$$

The sliding surface is given by

$$
S=\mathrm{K}_{1} \mathrm{e}_{1}+\mathrm{K}_{2} \mathrm{e}_{2}
$$

Where $\mathrm{x}_{1}$ is the inductor current and $\mathrm{x}_{2}$ is the output voltage, $\mathrm{e}_{1}$ is the voltage error, $\mathrm{e}_{2}$ is the current error $[6,7]$.

\section{Design of DSMC based Boost Converter}

The discrete model of boost converter based SMC is represented by the following equations $(8,9)$, equation (8) represents the discrete model when the switch is ON, equation (9) represents the discrete model when the switch is OFF. 


$$
\begin{aligned}
& \mathrm{x}_{1}[\mathrm{k}+1]=\mathrm{x}_{1}[\mathrm{k}]+\frac{\mathrm{T}}{\mathrm{L}}\left[\mathrm{V}_{\mathrm{in}}-(1-\mathrm{u}) \mathrm{x}_{2}\right] \\
& \mathrm{x}_{2}[\mathrm{k}+1]=\mathrm{x}_{2}[\mathrm{k}]-\frac{\mathrm{T}}{\mathrm{C}}\left[\frac{x_{\mathrm{z}}}{R}-(1-u) x_{1}\right] \\
& e_{1}=x_{2}-V_{\text {ref }} \\
& \mathrm{e}_{2}=x_{1}-\mathrm{I}_{\text {ref }}
\end{aligned}
$$

Where $I_{\text {ref }}=\frac{V_{\text {ref }}{ }^{2}}{\mathrm{R} v_{\text {in }}}$

The sliding surface is given by the equation (12)

$$
\mathrm{s}[\mathrm{k}]=\mathrm{K}_{1} \mathrm{e}_{1}[\mathrm{k}]+\mathrm{K}_{2} \mathrm{e}_{2}[\mathrm{k}]
$$

The system will converge when $\mathrm{S}[\mathrm{k}+1]<\mathrm{S}[\mathrm{k}]$, which can be obtained from Lyapnov Stability Criteria.

\section{Results and Discussion}

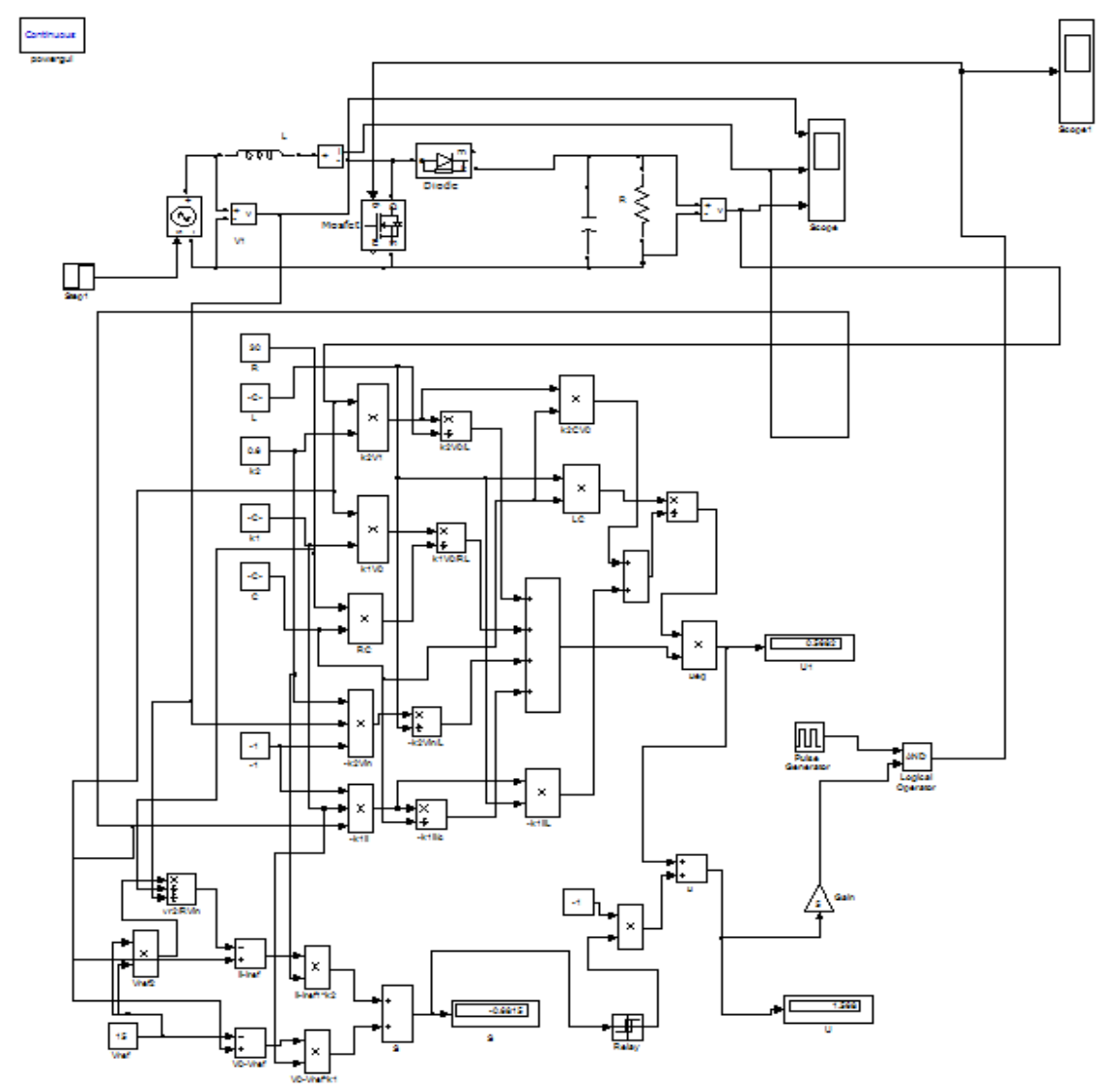

Figure 3. MATLAB SIMULINK Model of SMC for Boost Converter 


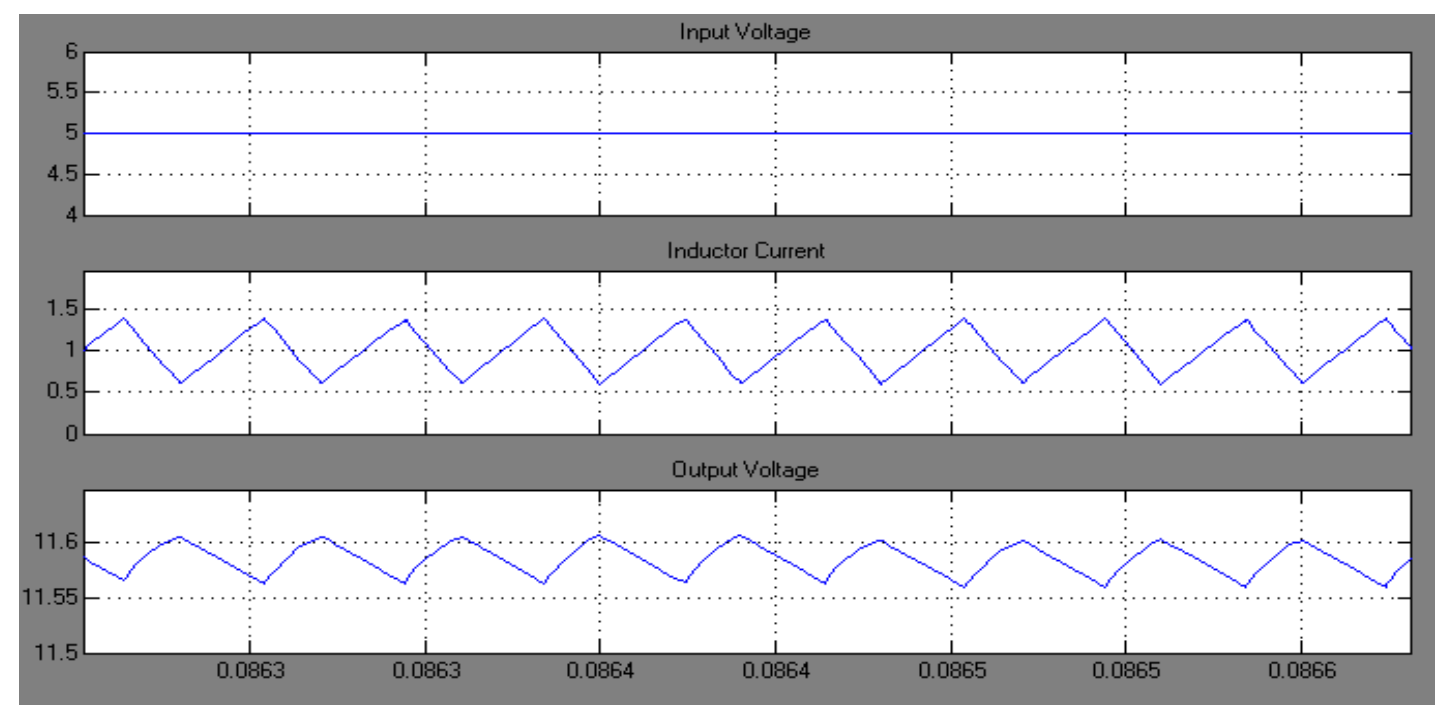

Figure 4. Simulated output of SMC based Boost Converter

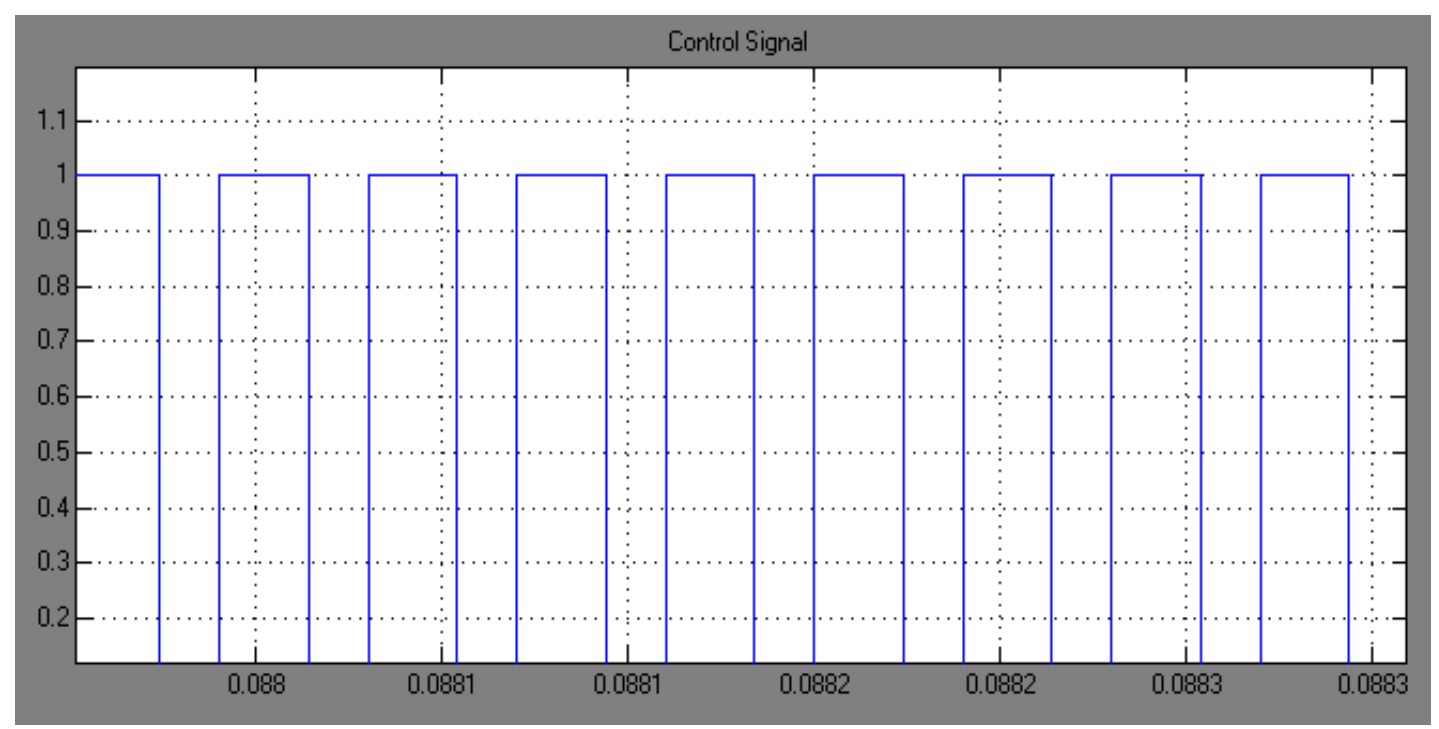

Figure 5. Control Signal for SMC based Boost Converter

Figure 3 shows MATLAB SIMULINK Model of SMC for Boost Converter, Figure 4 shows the simulated output of SMC based Boost Converter, Figure 5. Shows the control Signal for SMC based Boost Converter. Figure 6 shows the simulated output for SMC based Boost Converter with step change in input voltage from $5 \mathrm{v}$ to $6 \mathrm{v}$, Figure 7. Shows the control Signal for SMC based Boost Converter for step change in input voltage. Figure 8 shows the MATLAB SIMULINK Model of DSMC for Boost Converter, Figure 9 shows the simulated output of DSMC based Boost Converter; Figure 10 shows the control signal for DSMC based Boost Converter. Figure 11 shows the control signal for DSMC based Boost Converter for step input voltage change from $5 \mathrm{v}$ to $6 \mathrm{v}$. Figure 12 shows the control signal for DSMC based Boost Converter for step change in input $[8,9]$. 


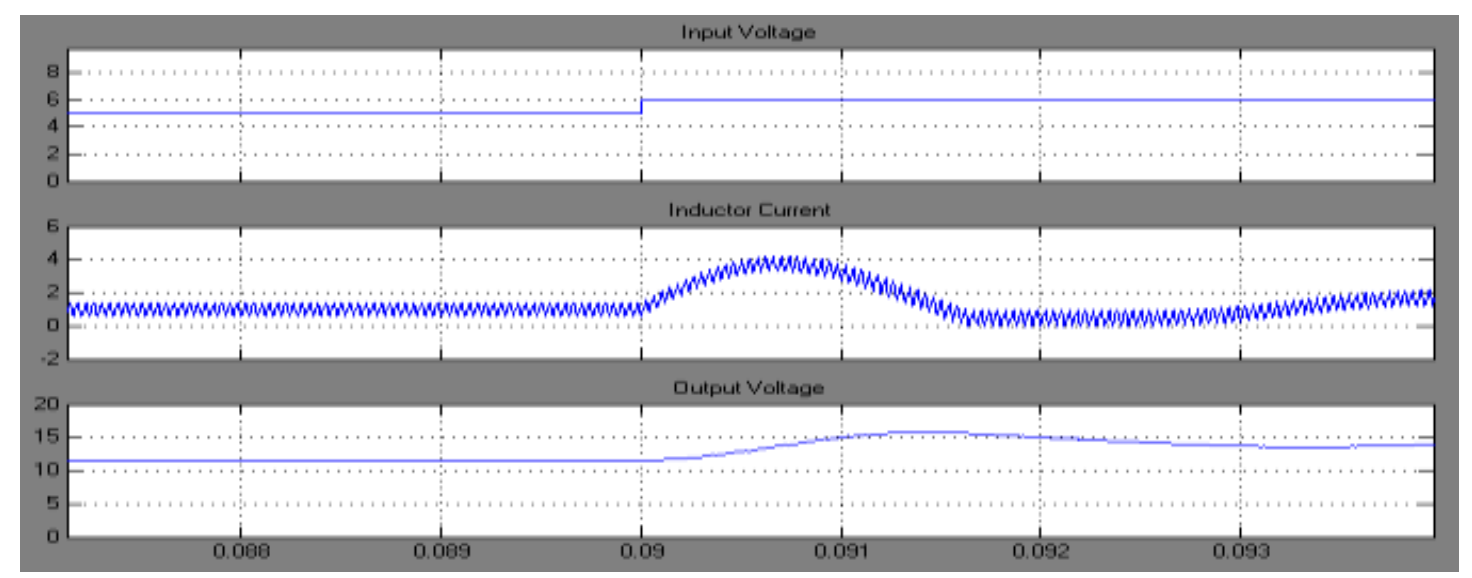

Figure 6. Simulated Output for SMC based Boost Converter with Step Change in Input

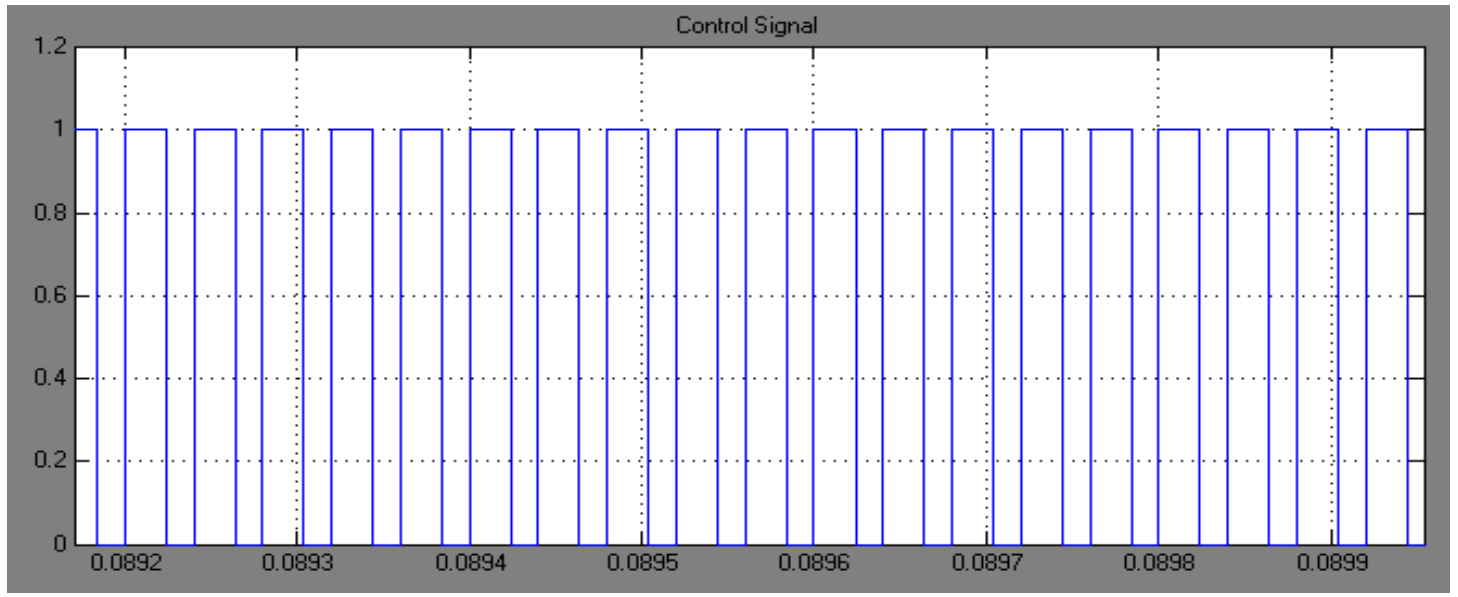

Figure 7. Control Signal for SMC based Boost Converter for Step Change in Input

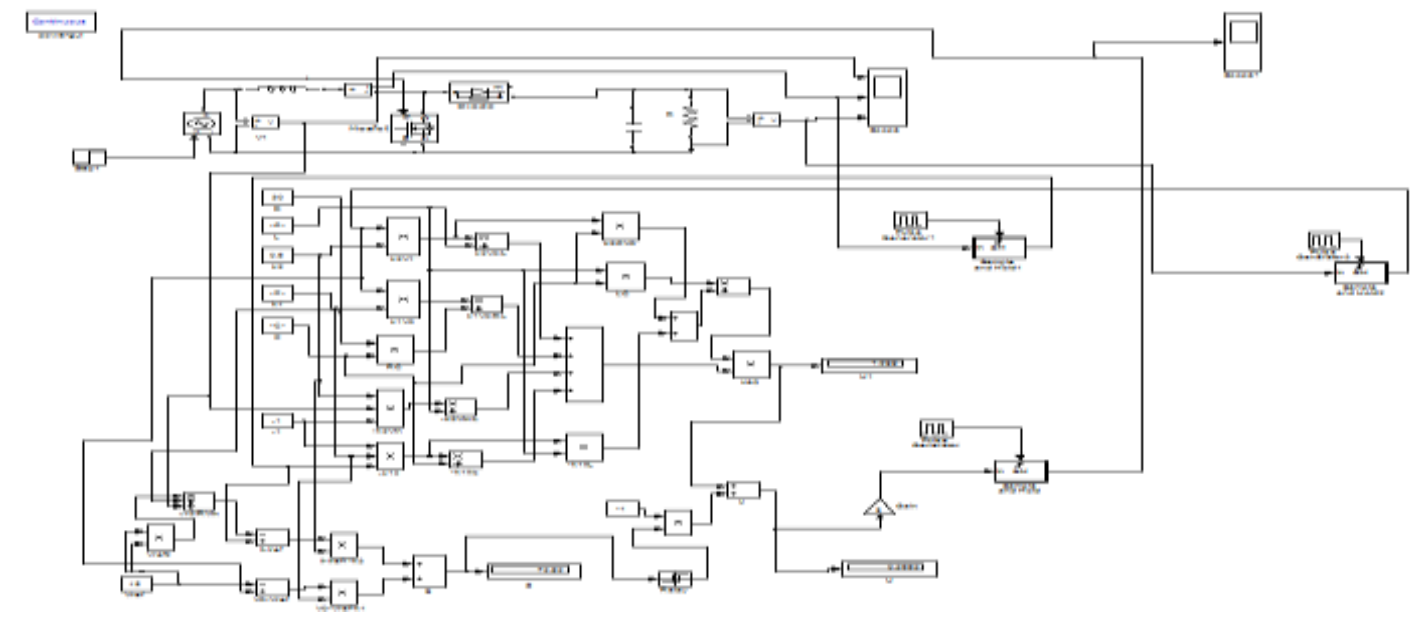

Figure 8. MATLAB SIMULINK Model of DSMC for Boost Converter 


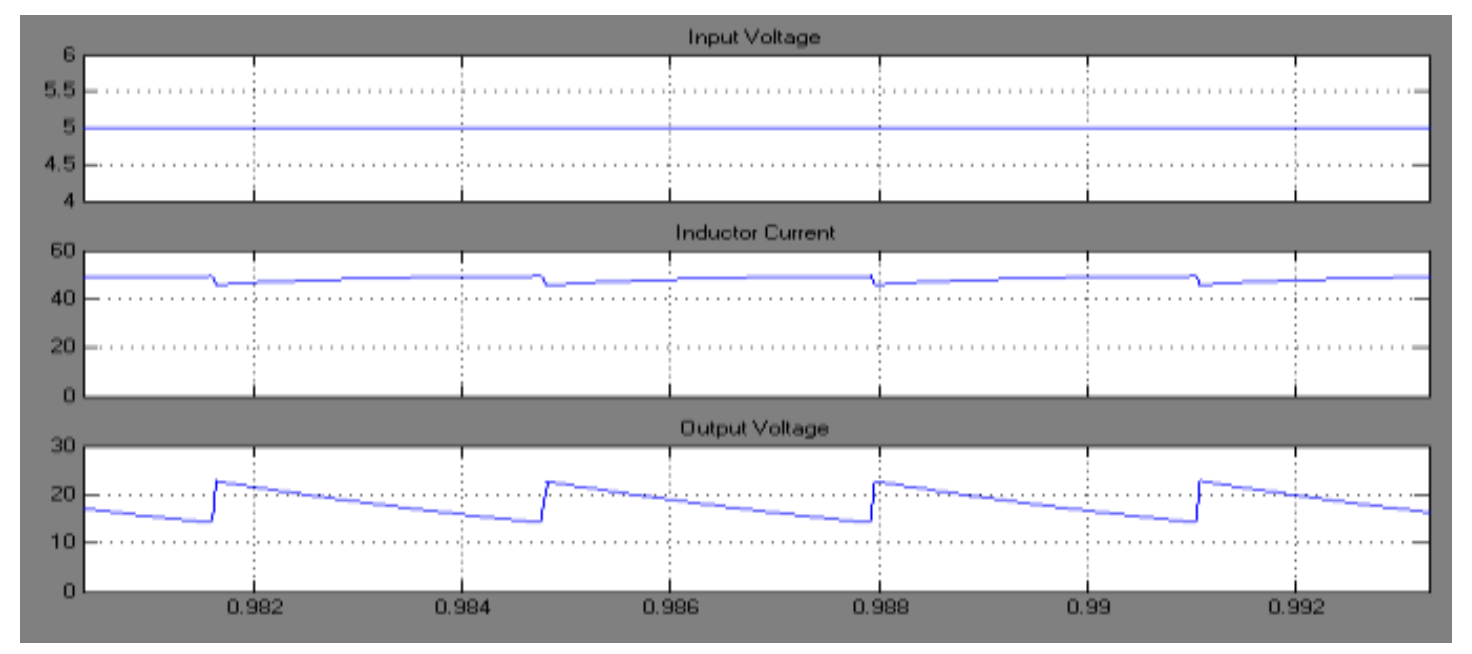

Figure 9. Simulated Output of DSMC based Boost Converter

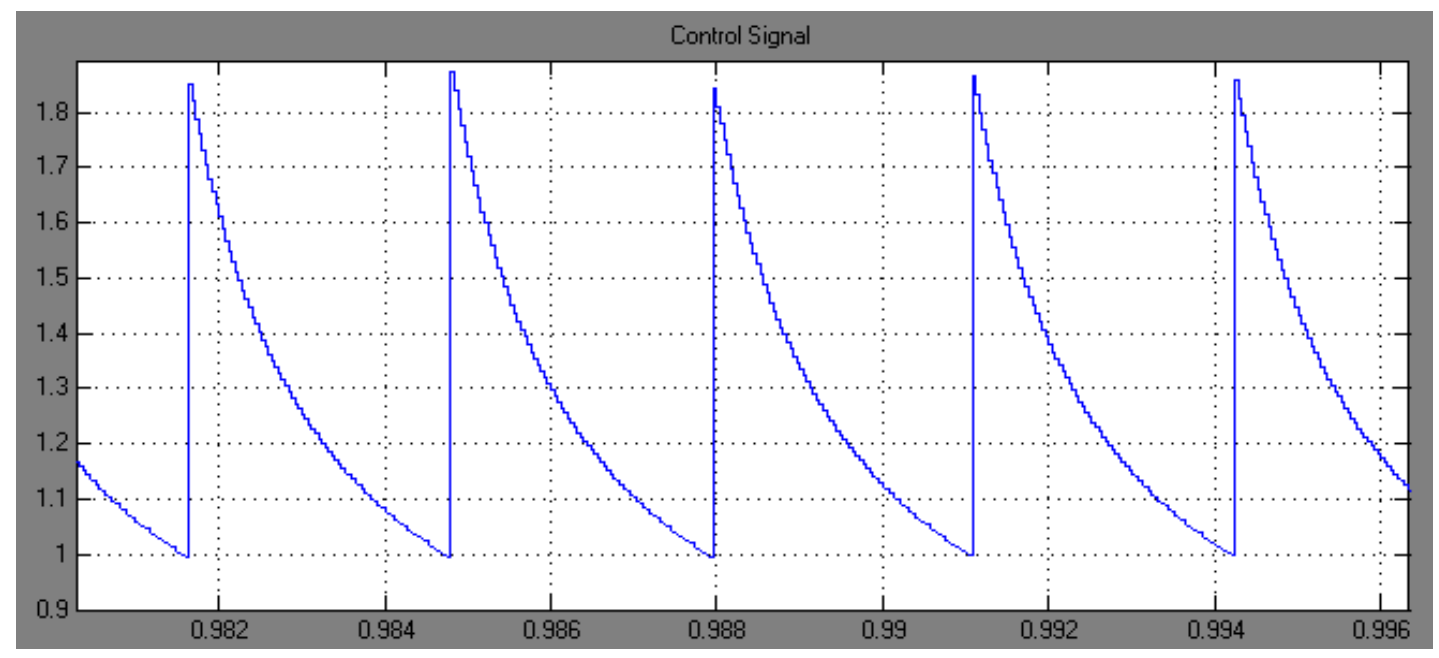

Figure 10. Control Signal for DSMC based Boost Converter

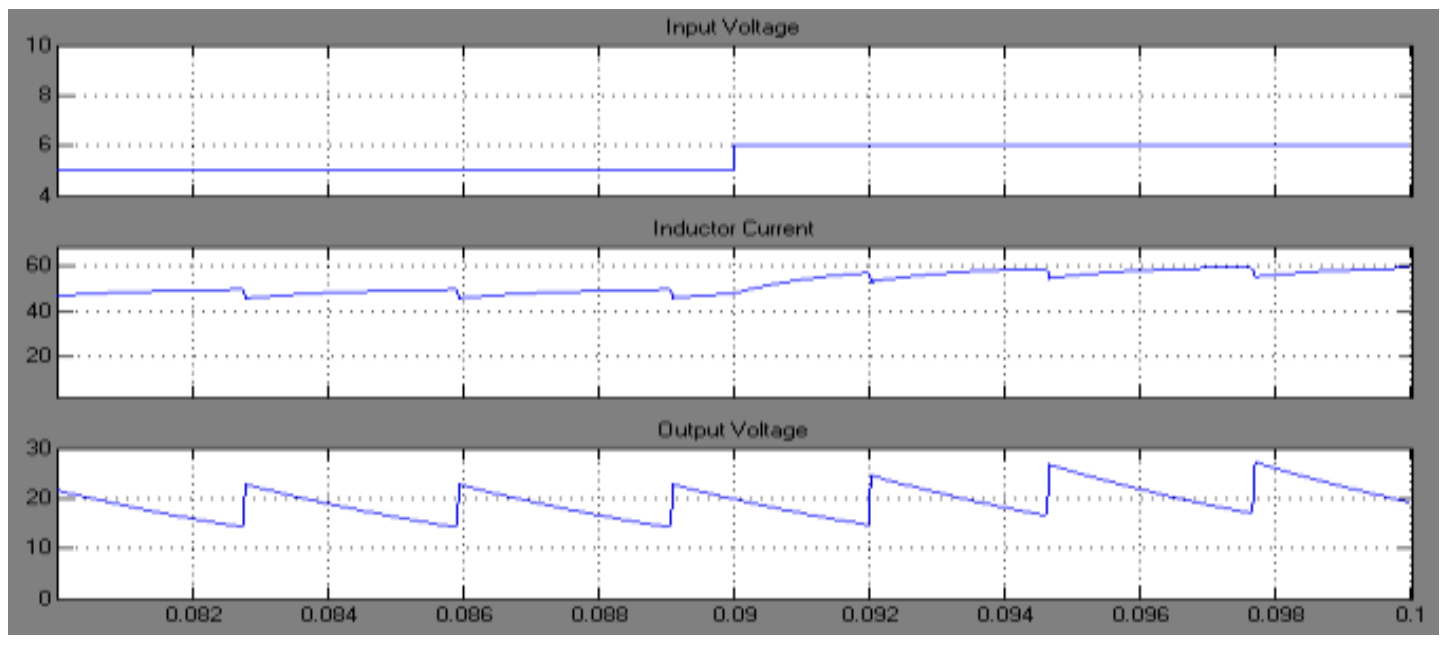

Figure 11. Control Signal for DSMC based Boost Converter for Step Input 


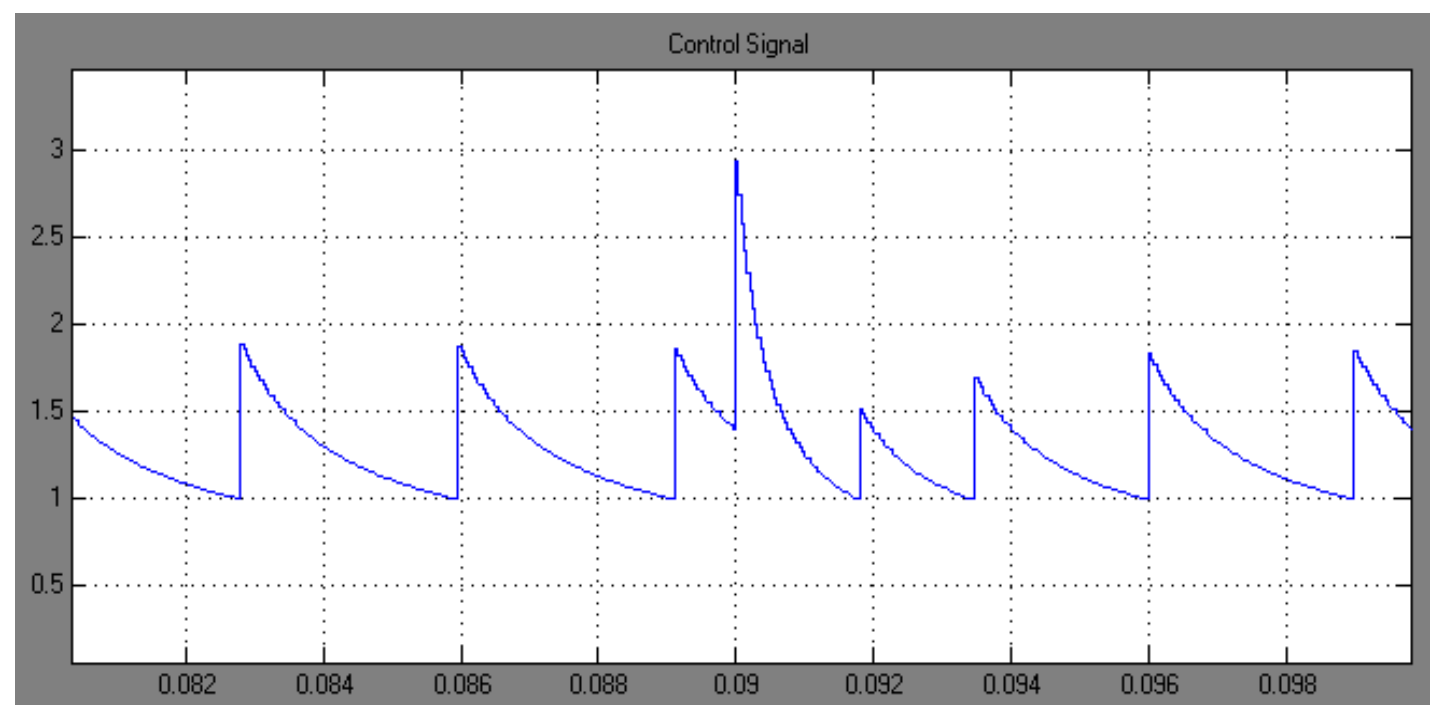

Figure 12. Control Signal for DSMC based Boost Converter for Step Change in Input

Table 1. Parameters Used for Boost Converter

\begin{tabular}{|c|c|}
\hline Parameters & Values \\
\hline $\mathrm{R}$ & $30 \Omega$ \\
\hline $\mathrm{L}$ & $150 \mu \mathrm{H}$ \\
\hline $\mathrm{C}$ & $220 \mu \mathrm{F}$ \\
\hline Sampling Frequency & $30 \mathrm{KHz}$ \\
\hline
\end{tabular}

\section{Conclusion}

Qualified analysis of DSMC over SMC is made and the response is shown in the above figures both the cases the output is getting boosted. When there is a step change in input from $5 \mathrm{v}$ to $6 \mathrm{v}$ the system response is very fast and it stabilizes in both the controllers which show the robustness of the system under uncertainty. The parameters used are $\mathrm{R}=30 \Omega, \mathrm{L}=150$ $\mu \mathrm{H}, \mathrm{C}=220 \mu \mathrm{F}, \mathrm{K}_{1}=0.667, \mathrm{~K}_{2}=0.6$ and the sampling frequency is $30 \mathrm{KHz}$. The response of DSMC has more ripples compared to SMC but regulation of output voltage is good in both the cases. The performance of the controller is good for the values of $K_{1}=0.565$ to 1 and $\mathrm{K}_{2}=0.2$ to 0.7 for both the controllers. To reduce the output ripple in DSMC sampling frequency has to be increased but at high sampling frequency discrete system will become continuous so there is a restriction for sampling frequency also. Even through ripple content is more it has other advantages like flexible control characteristics and simple digital control algorithm results in ease of implementation due to the development microcontroller and other types of digital controller. This result in overall system is cheap and economical. 


\section{References}

[1] V.I. Utkin, "Variable structure systems with sliding modes", IEEE Transactions on Automatic Control, vol. AC-22, no. 2, (1977), pp. 212-222.

[2] A. Leon-Masich, H. Valderrama-Blavi, J. M Bosque-Moncusi, J. Maixe-Aites and L. Martinez-Salamero, "Sliding-Mode-Control-Based Boost Converter for High-Voltage-Low-Power Applications", IEEE Transactions on Industrial Electronics, vol. 62, no. 1, (2015), pp. 229-237.

[3] B. Bandyopadhyay and B. Janardhanan, "Discrete-time sliding mode control", Springer, Berlin, ISBN-10 3540-28140-1, (2005).

[4] E. Vidal-Idiarte, A. Marcos-Pastor, G. Garcia, A. Cid-Pastor and L. Martinez-Salamero, "Discrete-time sliding-mode-based digital pulse width modulation control of a boost converter", IET Power Electronics, vol. 8, no. 5, (2015), pp. 708-714.

[5] K. Viji, A. Kumar and R. Nagaraj, "Enhanced Discrete Fuzzy Sliding Mode Control for Buck Converter", International Journal of Control Theory and Applications, vol.10, no.18, (2017), pp. 335-342.

[6] M. Teodorescu and D. Stanciu, "Sliding Coefficients Estimation for Fixed Frequency Sliding Mode Control of Boost Converter", IEEE The 9th International Symposium on Advanced Topics in Electrical Engineering, (2015), pp. 698-703.

[7] A. Karthikayini, S. Ramprasath and P. Rameshbabu, "Modeling and Simulation of PWM Based Sliding Mode Voltage Controller for Boost Converter in Continuous Conduction Mode", IEEE International Conference on Circuit, Power and Computing Technologies, (2015).

[8] M. Assaf, D. Seshachalam, D. Chandra and R. K. tripathi, "DC-DC Converters via MATLAB/SIMULINK", Proceedings of the 7th WSEAS international conference on Automatic control, modeling and simulation, (2005).

[9] D. Seshachalam, R. K. Tripathi and D. Chandra, "Practical Implimentation of Sliding Mode Control for Boost Converter", IEEE Asia Pacific Conference on Circuits and Systems, vol. 12, no. 4, (2006), pp. 650 653.

\section{Authors}

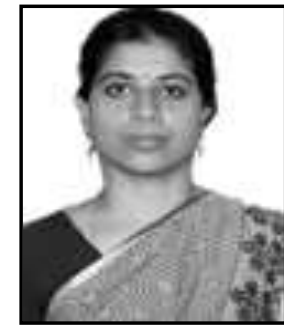

Viji. K, she is a Ph.D. scholar under Visvesvaraya Technological University India, currently she is working as an Assistant Professor, in Department of Electrical and Electronics Engineering, The Oxford College of Engineering, Bangalore, India. She completed her B.E. (Distinction) from Manonmaniam Sundaranar University India, M.E. (Distinction) from Anna University India. Her area of research is Non-linear Control Systems, Sliding mode Control Theory and Power Electronics.

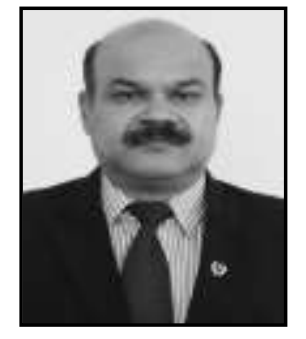

Anil Kumar, he completed his B E (Hons) from Thapar University Patiala India, M.E. (Distinction) from Pune University, India, PhD from Motilal Nehru National Institute of Technology Allahabad India. A passionate teacher and researcher he has been Head, Faculty of Electronics and is currently Director of AMITY School of Engg \& Technology AMITY University Uttar Pradesh Lucknow Campus. His current area of research are Advanced Nonlinear Control Theory, Sliding mode Control theory, Intelligent Control, aerospace Control, Microwave and Radar, Photonics sensors and Devices. 


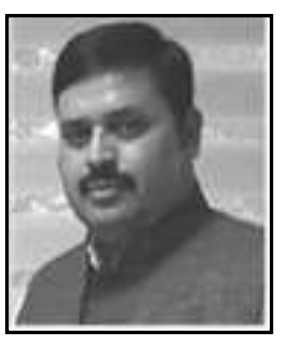

R Nagaraj, he obtained his $\mathrm{PhD}$ from Visvesvaraya Technological University in the field of Fault Tolerant Flight Controllers using Artificial Neural Network (ANN). His areas of interest include fault tolerant control, nonlinear control systems, neural networks and reconfigurable control. He was the national merit scholar and received academic excellence award from RSST and mentorship award from RV VLSI Design Center, Bangalore. Dr. Nagaraj is IEEE Senior Member, Life Member of Institution of Electronics \& Telecommunication Engineers, and Indian Society for Technical Education and Computer Society of India. 